\title{
New Tricorn \& Multicorns of Ishikawa Iterates
}

\author{
Yashwant S Chauhan \\ Asst. Professor \\ Computer Science \& Engg. \\ Department \\ G. B. Pant Engg. College, \\ Pauri Garhwal
}

\author{
Rajeshri Rana \\ Asst. Professor \\ Applied Science and Humanities \\ Department \\ G. B. Pant Engg. College, \\ Pauri Garhwal
}

\author{
Ashish Negi \\ Asst. Professor \\ Computer Science \& Engg. \\ Department \\ G. B. Pant Engg. College, \\ Pauri Garhwal
}

\begin{abstract}
We introduce in this paper the dynamics of Relative Superior Tricorn and Multicorns for Ishikawa iteration.
\end{abstract}

Keywords: Complex dynamics, Ishikawa Iteration, Relative Superior Tricorn and Relative Superior Multicorns.

\section{INTRODUCTION}

The word "Fractal" from Latin word "fractus" meaning "broken" was introduced in 1975 by mathematician Benoit B. Mandelbrot to describe irregular and intricate natural phenomenon as lunar landscapes, mountains, trees branching and coastlines etc. The object Mandelbrot set, given by Mandelbrot in 1979 and its relative object Julia set due to their beauty and complexity of their nature have become elite area of research nowadays.

Recently Shizuo [8], has presented the various properties of Multicorns and Tricorn along with beautiful figures. Shizuo has quoted the Multicorns as the generalized Tricorn or the Tricorn of higher order. The dynamics of antipolynomial $z \rightarrow \vec{z}^{d}+c$ of complex polynomial $z^{d}+c$, where $d \geq 2$, leads to interesting tricorn and multicorns antifractals with respect to function iteration (see [2] and [7, 8]). Tricorn are being used for commercial purpose, e.g. Tricorn mugs and Tricorn $\mathrm{T}$ shirts. Multicorns are symmetrical objects. Their symmetry has been studied by Lau and Schleicher [5].

The study of connectedness locus for antiholomorphic polynomials $\vec{z}^{2}+c$ defined as Tricorn, coined by Milnor, plays intermediate role between quadratic and cubic polynomials. Crowe etal.[1] considered it as in formal analogy with Mandelbrot set and named it as Mandel-bar set and also brought its features bifurcations along axes rather than at points. Milnor [6] found it as a real slice of cubic connected locus. Winters [16] showed it as boundary along the smooth arc. Superior Tricorn and Superior Multicorns using the Mann iterates rather than function iterates is studied and explored by A. Negi[9]. In this paper we introduce a new class of Relative Superior Tricorn and Relative Superior Multicorns using
Ishikawa iterates and also study their corresponding Relative Superior Julia sets.

\section{PRELIMINEARIES}

\subsection{Tricorn and Multicorns:}

Following the Milnor's study, Shizuo [8] has defined the Tricorn, as the connectedness locus for antiholomorphic polynomials, $z^{\prime n}+c$, where $n=2$.

Definition2.1: The Multicorns $A_{c}$, for the quadratic $A_{c}(z)=z^{\prime n}+c$ is defined as the collection of all $c \in C$ for which the orbit of the point 0 is bounded, that is, $A_{c}=\left\{c \in C: A_{c}(0)_{n=0,1,2,3, \ldots}\right.$ is bounded $\}$. An equivalent formulation is $A_{c}=\left\{c \in C: A_{c}(0)\right.$ not tends to $\infty$ as $\left.n \rightarrow \infty\right\}$

The Tricorn are special Multicorns when $n=2$. As quoted by Shizuo [8], the Tricorn plays an intermediate role between quadratic and cubic polynomials. As quoted by Devaney [2], iterations of the function $A_{c}=z^{\prime 2}+c$, using the Escape Time Algorithm, results in many strange and surprising structures. Devaney [2] has named it Tricorn and observed that $f\left(z^{\prime}\right)$, the conjugate function of $f(z)$, is antipolynomial. Further, its second iterates is a polynomial of degree 4 . Taking the initial choice $z_{0}$, one can iterate $A_{c}^{1}(z)$, resulting $z_{1}$ equals $z_{0}^{\prime 2}+c$, which can be written as $\left\{\left|z_{0}\right|^{2} / z_{0}\right\}^{2}+c$, since $z_{0}^{\prime} * z_{0}$ is equivalent to $\left\{\left|z_{0}\right|^{2}\right\}$, which gives $z_{1}$ equals $\left\{\left|z_{0}\right|^{4} / z_{0}{ }^{2}\right\}+c$. Using this value one can state the conjugate of $z_{1}$ as $z_{1}^{\prime}=\left\{\left|z_{0}\right|^{4} / z_{0}^{\prime 2}\right\}+c^{\prime}$, resulting $z_{0}^{2}+c^{\prime}$. Now the second iterate can be stated as $A^{2}{ }_{c}(z)$ which is equal to $z_{1}^{\prime 2}+c$, on simplifying, one can get $\left\{z_{0}{ }^{2}+c^{\prime}\right\}^{2}+c$, further, $z_{0}{ }^{4}+2 z_{0}{ }^{2} c^{\prime}+c^{\prime 2}+c$, 
which is a polynomial of degree 4 in $z$. Further, Devaney [2], has observed that the function $z^{\prime 2}+c$ is conjugate of $z^{\prime 2}+d$, where $d=e^{2 \pi i / 3}$, which shows that the Tricorn is symmetric under rotations through angle $2 \pi / 3$. The critical point for $A_{c}$ is 0 , since $c=A_{c}(0)$ has only one preimage whereas any other $w \in C$, has two preimages.

Definition2.2: Ishikawa Iteration [3]: Let $X$ be a subset of real or complex numbers and $f: X \rightarrow X$.

For $x_{0} \in X$, we have the sequences $\left\{x_{n}\right\}$ and $\left\{y_{n}\right\}$ in $\mathrm{X}$ in the following manner:

$y_{n}=s_{n}^{\prime} f\left(x_{n}\right)+\left(1-s_{n}^{\prime}\right) x_{n}$

$x_{n}=s_{n-1} f\left(y_{n-1}\right)+\left(1-s_{n-1}\right) x_{n-1}$

where $0 \leq s_{n}^{\prime} \leq 1,0 \leq s_{n} \leq 1$ and $\quad s_{n}^{\prime} \& \quad s_{n}$ are both convergent to non zero number.

Definition 2.3: The sequences $x_{n}$ and $y_{n}$ constructed above is called Ishikawa sequences of iterations or Relative superior sequences of iterates. We denote it by $R S O\left(x_{0}, s_{n}, s_{n}^{\prime}, t\right)$.

Notice that $\operatorname{RSO}\left(x_{0}, s_{n}, s_{n}^{\prime}, t\right)$ with $s_{n}^{\prime}=1$ is $R S O\left(x_{0}, s_{n}, t\right)$ i.e. Mann's orbit and if we place $s_{n}=s_{n}^{\prime}=1$ then $R S O\left(x_{0}, s_{n}, s_{n}^{\prime}, t\right)$ reduces to $O\left(x_{0}, t\right)$.

We remark that Ishikawa orbit $R S O\left(x_{0}, s_{n}, s_{n}^{\prime}, t\right)$ with $\quad s_{n}^{\prime}=1 / 2 \quad$ is Relative Superior orbit. Now we define Mandelbrot sets for function with respect to Ishikawa iterates. We call them as Relative Superior Mandelbrot sets.

Definition 2.3: Relative Superior Mandelbrot set RSM for the function of the form $Q_{c}(z)=z^{n}+c$, where $\mathrm{n}=$ $1,2,3,4 \ldots$ is defined as the collection of $c \in C$ for which the orbit of 0 is bounded i.e.

$$
R S M=\left\{c \in C: Q_{c}^{k}(0): k=0,1,2 \ldots\right\} \text { is bounded. }
$$

Here we present the study of Relative Superior Julia set of Relative Superior Tricorn by using the Escape Time Algorithm with respect to Ishikawa Iterates.

Now, we define escape criterions for these sets.

2.4 Escape Criterion: We obtain a general escape criterion for polynomials of the form $G_{c}(z)=z^{n}+c$

Theorem 2.1: For general function $G_{c}(z)=z^{n}+c, \mathrm{n}$ $=1,2,3,4 \ldots$ where $0<s \leq 1,0<s^{\prime}<1$ and $c$ is the complex plane.

$$
\begin{aligned}
& \text { Define } z_{1}=(1-s) z+s G_{c}(z) \\
& \vdots \\
& z_{n}=(1-s) z_{n-1}+s G_{c}\left(z_{n-1}\right)
\end{aligned}
$$

The general escape criterion is $\max \left\{|c|,(2 / s)^{1 / n+1},\left(2 / s^{\prime}\right)^{1 / n+1}\right\}$.

Proof: We shall prove this theorem by induction:

For $\mathrm{n}=1$, we get $G_{c}(z)=z+c$. So, the escape criterion is $|c|$, which is obvious, i.e. $|z|>\max \{|c|, 0,0\}$

For $\mathrm{n}=2$, we get $G_{c}(z)=z^{2}+c$. So, the escape criterion is $|z|>\max \left\{|c|, 2 / s, 2 / s^{\prime}\right\}$

For $\mathrm{n}=3$, we get $G_{c}(z)=z^{3}+c$. So, the escape criterion is $|z|>\max \left\{|c|,(2 / s)^{1 / 2},\left(2 / s^{\prime}\right)^{1 / 2}\right\}$.

Assume that the theorem is true for $\mathrm{n}=1,2,3,4 \ldots$ So, let $G_{c}(z)=z^{n+1}+c$ and $|z| \geq|c|>(2 / s)^{1 / n+1}$ as well as $|z| \geq|c|>\left(2 / s^{\prime}\right)^{1 / n+1}$ exists.

Then, $\quad\left|G_{n}(z)\right|=\left|\left(1-s^{\prime}\right) z+s^{\prime} G_{c}^{\prime}(z)\right| \quad$ where $G_{c}^{\prime}(z)=z^{n+1}+c$

$=\left|z-s^{\prime} z+s^{\prime}\left(z^{n+1}+c\right)\right|$

$\geq\left|s^{\prime} z^{n+1}-s^{\prime} z+z\right|-s^{\prime}|c|$

$\geq|z|\left(s^{\prime}\left|z^{n}\right|-s^{\prime}+1\left|-s^{\prime}\right| z \mid \quad(\because|z| \geq|c|)\right.$

$\geq|z|\left\{\left(s^{\prime}\left|z^{n}\right|+\left|s^{\prime}\right|-|1|\right\}-s^{\prime}|z|\right.$

$\geq|z|\left(s^{\prime}\left|z^{n}\right|+s^{\prime}-1-s^{\prime}\right)$

$\geq|z|\left(s^{\prime}\left|z^{n}\right|-1\right)$

Now, $\left|z_{1}\right|=\left|(1-s) z+s G_{n}(z)\right|$

$=|(1-s) z+s| z\left|\left(s^{\prime}\left|z^{n}\right|-1\right)\right|$

$=|z-s z+s| z\left|\cdot s^{\prime}\right| z^{n}|-s| z||$

$\geq(|z|-s|z|)+\left(s s^{\prime}\left|z^{n+1}\right|-s|z|\right)$

$\geq\left(s s^{\prime}\left|z^{n+1}\right|+|z|\right)$

$\geq\left|s s^{\prime} z^{n+1}\right|-|z|$

$\geq|z|\left(s s^{\prime}\left|z^{n}\right|-1\right)$

Since $|z|>(2 / s)^{1 / n} ;|z|>\left(2 / s^{\prime}\right)^{1 / n}$ and $|z|>\left(2 / s s^{\prime}\right)^{1 / n}$.So $|z|>\left(2 / s s^{\prime}\right)^{1 / n}, \quad$ therefore $\left(s s^{\prime}\left|z^{n}\right|-1\right)>1$

Hence, for some $\lambda>0$, we have $\left(s s^{\prime}\left|z^{n}\right|-1\right)>1+\lambda$. Thus, $\left|z_{1}\right|>(1+\lambda)|z|$ 


$$
\begin{aligned}
& \vdots \\
& \left|z_{n}\right|=(1+\lambda)^{n}|z|
\end{aligned}
$$

Therefore, the Ishikawa orbit of $\mathrm{z}$ under the iteration of $z^{n+1}+c$ tends to infinity. Hence $|z|>\max \left\{|c|,(2 / s)^{1 / n},\left(2 / s^{\prime}\right)^{1 / n}\right\}$ is the escape criterion. This proves the theorem.

Corollary 2.1: $\quad$ Suppose that $|c|>(2 / s)^{1 / n-1}$ and $|c|>\left(2 / s^{\prime}\right)^{1 / n-1}$ exists. Then, the Relative Superior orbit $\operatorname{RSO}\left(G_{c}, 0, s, s^{\prime}\right)$ escapes to infinity.

Corollary2.2: Assume that

$\left|z_{k}\right|>\max \left\{|c|,(2 / s)^{1 / k-1},\left(2 / s^{\prime}\right)^{1 / k-1}\right\}$ for some

$k \geq 0$. Then $\left|z_{k+1}\right|>\gamma\left|z_{k}\right|$ and $\left|z_{n}\right| \rightarrow \infty$, as

$n \rightarrow \infty$. This corollary gives an algorithm for computing the Relative Superior Mandelbrot sets for the functions of the form $G_{c}(z)=z^{n}+c, \mathrm{n}=1,2,3,4 \ldots$

The purpose of this paper is to visualize the relative superior antifractals, i.e., antifractals with respect to relative superior orbit and to analyze the pattern of symmetry among them.

\section{GEOMETRY OF RELATIVE SUPERIOR TRICORNS AND MULTICORNS}

The results of plotting the Relative Superior Mandelbrot set for the function $A_{c}$ using Ishikawa Iterates, gives us the Tricorned like structure, hence, it can be named as Relative Superior Tricorn. Crowe et. al [12], has considered it in formal analogy with Mandelbrot set and named it "Mandelbar set". The general escape criterion for

higher powers of polynomials, $A_{c}(z)=z^{\prime n}+c$ where $\mathrm{n}$ is the degree of the polynomial, is given as $\max \left\{|c|,(2 / s)^{1 / n},\left(2 / s^{\prime}\right)^{1 / n}\right\}$ This can be used as the escape criterion for the function $A_{c}(z)$.We derive Relative Superior Multicorns using this escape criteria. We have used the same escape criterion for generating the new Tricorn for which the condition is $\max \left\{|c|, 2 / s, 2 / s^{\prime}\right\}$.

The characteristics of the Relative Superior Julia set for a point inside the Relative Superior Tricorn and Multicorns can be given by observing the Relative Superior Tricorn. We know that, if $c$ lies in $A_{c}$, the orbit of 0.0 does not escape to infinity. Hence we can say that if $c$ does not lie in $A_{c}$ then the Relative Superior Julia set $J_{c}$ for Relative Superior Tricorn, is a Cantor set. The Relative Superior Julia set of $A_{c}$ is either connected or totally disconnected, depending on, whether the orbit of 0 is bounded or escapes to infinity. We know that every Relative Superior Julia set is either a:

- Primary Relative Superior Julia set, or

- Secondary Relative Superior Julia set

Primary Relative Superior Julia set are the Relative superior Julia set for the points attached to the primary ovoid of the Relative Superior Tricorn, whereas the name secondary Relative Superior Julia set can be given to those Julia set which belongs to the ovoid attached to the primary ovoid. We study here the primary Relative Superior Julia set for Relative Superior Tricorn (See Section 6). Further, we observe that the Relative Superior Julia set for Relative superior Tricorn consists of all c-values for which $J_{c}$ is connected, or the orbit of 0.0 under $z^{\prime 2}+c$ does not tend to infinity.

We see that the Relative Superior Tricorn consists of three main ovoids. Further, these ovoids can be named as primary ovoids of Relative Superior Tricorn. The Relative superior Tricorn and Relative Superior Multicorns contain the Main body having an ovoid attached to the main body. Here we want to mention that the ovoid are connected to the main body in a different way than that in the Mandelbrot set.

Here, we are presenting the observation in the study of the Relative Superior Tricorn and Relative Superior Multicorns from the figures mentioned in Section 5.

- Here we notice that the number of ovoids in the Relative Superior Tricorn and Relative Superior Multicorns is $\mathrm{n}+1$, where $\mathrm{n}$ is the power of $z^{\prime}$.

- As the value of $s$ tend to 1 and s' tends to 1 , the Relative Superior Tricorn and Relative Superior Multicorns converts to the general Tricorn and general Multicorns, in which all the branches are similar, hence we can say that the Relative Superior Tricorn and Relative Superior Multicorns is the general case of the usual Tricorn and Multicorns.

- $\quad$ Starting with $A_{c}(z)=z^{\prime n}+c$, for $\mathrm{n}=2$ and $\mathrm{s}<1, \mathrm{~s}^{\prime}<1$ and applying the Ishikawa iterates we see that the Relative Superior Mandelbrot set of this function is also a Tricorned set but the small bulbs at the ovoid vanishes as the value of $s^{\prime}$ becomes smaller but the symmetry of the Relative Superior Tricorn and Relative Superior Multicorns is not distorted.

- We also observe that for $n$ is odd we have symmetry about both $\mathrm{X}$ and $\mathrm{Y}$ axis but for $n$ is even the symmetry is maintained only along $\mathrm{X}$ axis. 


\section{FIXED POINTS:}

4.1 Fixed points of quadratic polynomial

Table 1: Orbit of $F(z)$ for $s=1, s^{\prime}=1$ at $z_{0=}=\mathbf{- 0 . 3 5 - 0 . 0 3 1 2 5 i}$

\begin{tabular}{|c|c|c|c|}
\hline $\begin{array}{c}\text { Number of } \\
\text { iteration } i\end{array}$ & $|\mathrm{~F}(\mathrm{z})|$ & $\begin{array}{c}\text { Number of } \\
\text { iteration } i\end{array}$ & $|\mathrm{~F}(\mathrm{z})|$ \\
\hline 1 & 0.35139 & 5 & 0.11271 \\
\hline 2 & 0.14891 & 6 & 0.1127 \\
\hline 3 & 0.11487 & 7 & 0.1127 \\
\hline 4 & 0.11281 & 8 & 0.1127 \\
\hline
\end{tabular}

Here we observe that the value converges to a fixed point after 06 iterations

Figure 1: Orbit of $F(z)$ for $s=1, s^{\prime}=1$ at $\mathbf{z}_{0=-\mathbf{0 . 3 5 - 0 . 0 3 1 2 5 i}}$

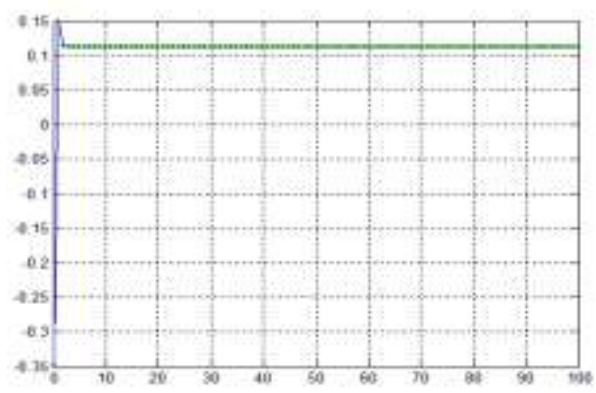

Table 2: Orbit of $\mathrm{F}(\mathrm{z})$ for $\mathbf{s}=\mathbf{0 . 5}, \mathbf{s}^{\prime}=\mathbf{0 . 7}$ at $z_{0}=0.07056911734+0.03212328902 i$

\begin{tabular}{|c|c|c|c|}
\hline $\begin{array}{c}\text { Number of } \\
\text { iteration } \mathrm{i}\end{array}$ & $|\mathrm{F}(\mathrm{z})|$ & $\begin{array}{c}\text { Number of } \\
\text { iteration } \mathrm{i}\end{array}$ & $|\mathrm{F}(\mathrm{z})|$ \\
\hline 1 & 0.077536 & 14 & 0.24658 \\
\hline 2 & 0.14361 & 15 & 0.24673 \\
\hline 3 & 0.18384 & 16 & 0.2469 \\
\hline 4 & 0.20785 & 17 & 0.24694 \\
\hline 5 & 0.22246 & 18 & 0.24696 \\
\hline 6 & 0.23151 & 19 & 0.24698 \\
\hline 7 & 0.23717 & 20 & 0.24699 \\
\hline 8 & 0.24075 & 21 & 0.24699 \\
\hline 9 & 0.24301 & 22 & 0.247 \\
\hline 10 & 0.24446 & 23 & 0.247 \\
\hline 11 & 0.24538 & 24 & 0.247 \\
\hline 12 & 0.24596 & 25 & 0.247 \\
\hline 13 & 0.24634 & 26 & 0.247 \\
\hline
\end{tabular}

Here we observe that the value converges to a fixed point after 22 iterations

Figure 2: Orbit of $\mathrm{F}(\mathrm{z})$ for $\mathbf{s}=\mathbf{0 . 5}, \mathrm{s}^{\prime}=\mathbf{0 . 7}$ at $z_{0}=0.07056911734+0.03212328902 i$

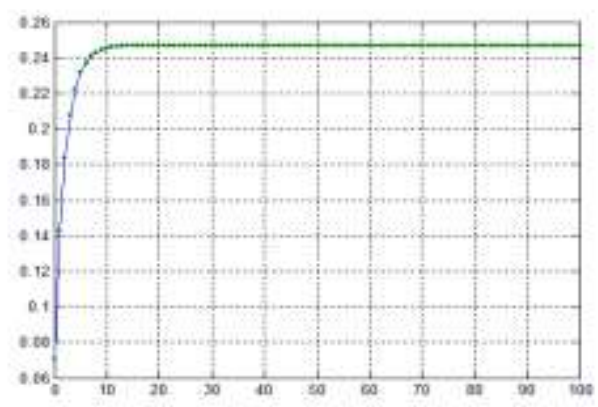

Table 3: Orbit of $F(z)$ for $\mathbf{s}=\mathbf{0 . 6}, \mathbf{s}^{\prime}=\mathbf{0 . 4}$ at

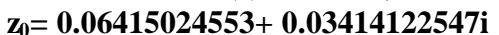

\begin{tabular}{|c|c|c|c|}
\hline $\begin{array}{c}\text { Number of } \\
\text { iteration } \mathrm{i}\end{array}$ & $|\mathrm{F}(\mathrm{z})|$ & $\begin{array}{c}\text { Number of } \\
\text { iteration } \mathrm{i}\end{array}$ & $|\mathrm{F}(\mathrm{z})|$ \\
\hline 1 & 0.07267 & 16 & 0.23638 \\
\hline 2 & 0.13743 & 17 & 0.23643 \\
\hline 3 & 0.17641 & 18 & 0.23646 \\
\hline 4 & 0.19914 & 19 & 0.23648 \\
\hline 5 & 0.21289 & 20 & 0.23649 \\
\hline 6 & 0.22143 & 21 & 0.2365 \\
\hline 7 & 0.22681 & 22 & 0.2365 \\
\hline 8 & 0.23025 & 23 & 0.23651 \\
\hline 9 & 0.23246 & 24 & 0.23651 \\
\hline 10 & 0.23389 & 25 & 0.23651 \\
\hline 11 & 0.23481 & 26 & 0.23651 \\
\hline 12 & 0.2354 & 27 & 0.23651 \\
\hline 13 & 0.23579 & 28 & 0.23651 \\
\hline 14 & 0.23604 & 29 & 0.23651 \\
\hline 15 & 0.23621 & 30 & 0.23651 \\
\hline
\end{tabular}

Here the value converges to a fixed point after 23 iterations

Figure 3: Orbit of $\mathrm{F}(\mathrm{z})$ for $\mathrm{s}=\mathbf{0 . 6}, \mathrm{s}^{\prime}=\mathbf{0 . 4}$ at $\mathrm{z}_{0}=0.06415024553+0.03414122547 \mathrm{i}$

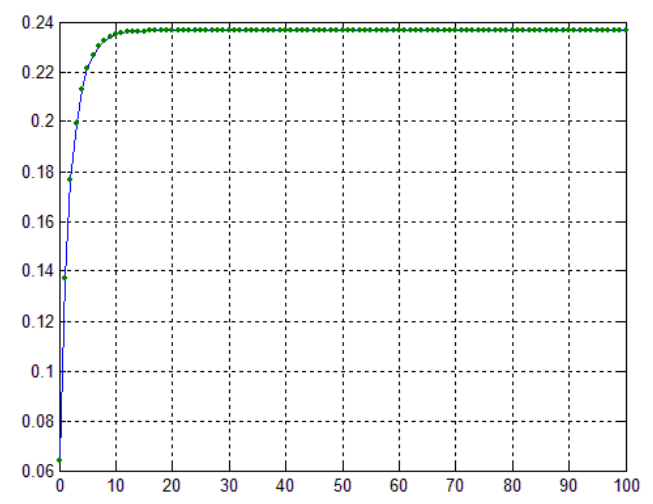

4.2 Fixed points of Cubic polynomial

Table 1: Orbit of $F(z)$ for $s=1, s^{\prime}=1$ at $\mathrm{z}_{0}=\mathbf{- 0 . 4 4 3 5 0 8 7 5 5 7 - 0 . 4 1 4 0 9 0 5 3 2 5 i}$

\begin{tabular}{|c|c|c|c|}
\hline $\begin{array}{c}\text { Number of } \\
\text { iteration } i\end{array}$ & $|\mathrm{~F}(\mathrm{z})|$ & $\begin{array}{c}\text { Number of } \\
\text { iteration } i\end{array}$ & $|\mathrm{~F}(\mathrm{z})|$ \\
\hline 1 & 0.60677 & 6 & 0.10103 \\
\hline 2 & 0.095583 & 7 & 0.10103 \\
\hline 3 & 0.10102 & 8 & 0.10103 \\
\hline 4 & 0.10103 & 9 & 0.10103 \\
\hline 5 & 0.10103 & 10 & 0.10103 \\
\hline
\end{tabular}

Here the value converges to a fixed point after 04 iterations 
Figure 1: Orbit of $F(z)$ for $\mathbf{s}=\mathbf{1}, \mathbf{s}^{\prime}=\mathbf{1}$ at $z_{0}=\mathbf{- 0 . 4 4 3 5 0 8 7 5 5 7 - 0 . 4 1 4 0 9 0 5 3 2 5 i}$

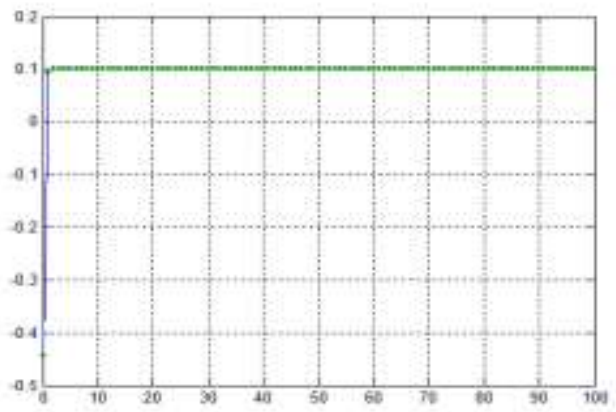

Table 2: Orbit of $\mathrm{F}(\mathrm{z})$ for $\mathbf{s}=\mathbf{0 . 8}$ and $\mathrm{s}^{\prime}=\mathbf{0 . 2}$ at

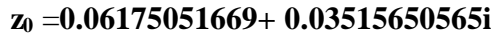

\begin{tabular}{|c|c|c|c|}
\hline $\begin{array}{c}\text { Number of } \\
\text { iteration } \mathrm{i}\end{array}$ & $|\mathrm{F}(\mathrm{z})|$ & $\begin{array}{c}\text { Number of } \\
\text { iteration } \mathrm{i}\end{array}$ & $|\mathrm{F}(\mathrm{z})|$ \\
\hline 1 & 0.071057 & 7 & 0.13392 \\
\hline 2 & 0.11487 & 8 & 0.13394 \\
\hline 3 & 0.12861 & 9 & 0.13395 \\
\hline 4 & 0.13244 & 10 & 0.13395 \\
\hline 5 & 0.13353 & 11 & 0.13395 \\
\hline 6 & 0.13383 & 12 & 0.13395 \\
\hline
\end{tabular}

Here the value converges to a fixed point after 09 iterations

Figure 2: Orbit of $F(z)$ for $\mathbf{s}=\mathbf{0 . 8}$ and $\mathrm{s}^{\prime}=\mathbf{0 . 2}$ at $\mathrm{z}_{0}=0.06175051669+0.03515650565 \mathrm{i}$

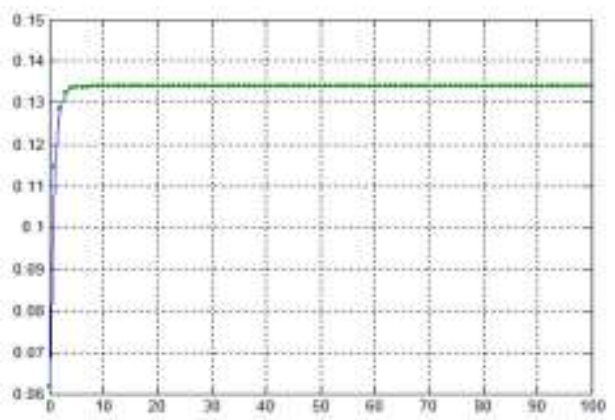

Table 3: Orbit of $F(z)$ for $s=0.5, s^{\prime}=0.4$ at $\mathrm{z}_{0}=\mathbf{- 0 . 0 1 3 4 1 9 1 2 2 5 4 + 0 . 0 0 1 0 1 7 6 6 6 0 9 2 \mathrm { i }}$

\begin{tabular}{|c|c|c|c|}
\hline $\begin{array}{c}\text { Number of } \\
\text { iteration } \mathrm{i}\end{array}$ & $|\mathrm{F}(\mathrm{z})|$ & $\begin{array}{c}\text { Number of } \\
\text { iteration } \mathrm{i}\end{array}$ & $|\mathrm{F}(\mathrm{z})|$ \\
\hline 1 & 0.013458 & 12 & 0.21207 \\
\hline 2 & 0.09368 & 13 & 0.2122 \\
\hline 3 & 0.14876 & 14 & 0.21228 \\
\hline 4 & 0.17784 & 15 & 0.21232 \\
\hline 5 & 0.19348 & 16 & 0.21235 \\
\hline 6 & 0.20199 & 17 & 0.21236 \\
\hline 7 & 0.20665 & 18 & 0.21236 \\
\hline 8 & 0.20922 & 19 & 0.21236 \\
\hline 9 & 0.21063 & 20 & 0.21237 \\
\hline 10 & 0.21141 & 21 & 0.21237 \\
\hline 11 & 0.21184 & 22 & 0.21237 \\
\hline
\end{tabular}

Here the value converges to a fixed point after 20 iterations
Figure 3: Orbit of $\mathrm{F}(\mathrm{z})$ for $\mathrm{s}=\mathbf{0 . 5}, \mathrm{s}^{\prime}=\mathbf{0 . 4}$ at $z_{0}=-\mathbf{0 . 0 1 3 4 1 9 1 2 2 5 4 + 0 . 0 0 1 0 1 7 6 6 6 0 9 2 i}$

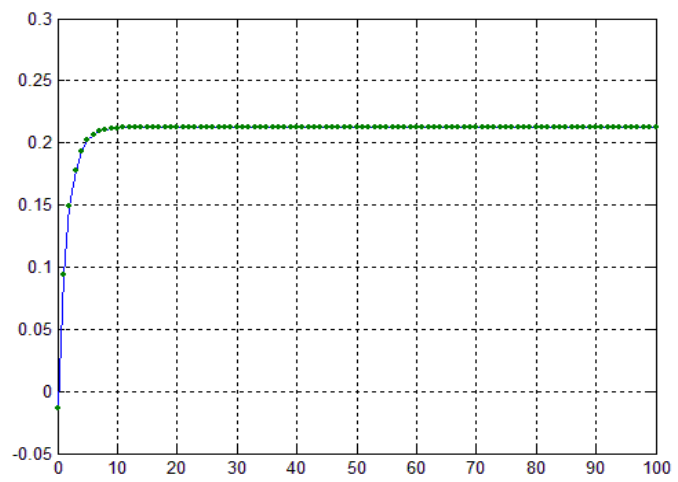

4.3 Fixed points of Bi-quadratic polynomial

Table 1: Orbit of $F(z)$ for $s=1, s^{\prime}=1$ at $z_{0}=-\mathbf{0 . 1 8 8 6 5 6 8 9 6 6}+\mathbf{0 . 5 6 7 8 1 3 3 5 1 2 i}$

\begin{tabular}{|c|c|c|c|}
\hline $\begin{array}{c}\text { Number of } \\
\text { iteration } i\end{array}$ & $|\mathrm{~F}(\mathrm{z})|$ & $\begin{array}{c}\text { Number of } \\
\text { iteration } i\end{array}$ & $|\mathrm{~F}(\mathrm{z})|$ \\
\hline 1 & 0.59833 & 5 & 0.1001 \\
\hline 2 & 0.098889 & 6 & 0.1001 \\
\hline 3 & 0.1001 & 7 & 0.1001 \\
\hline 4 & 0.1001 & 8 & 0.1001 \\
\hline
\end{tabular}

Here the value converges to a fixed point after 03 iterations

Figure 1: Orbit of $F(z)$ for $s=1, s^{\prime}=1$ at $\mathrm{z}_{0}=\mathbf{- 0 . 1 8 8 6 5 6 8 9 6 6}+\mathbf{0 . 5 6 7 8 1 3 3 5 1 2} i$

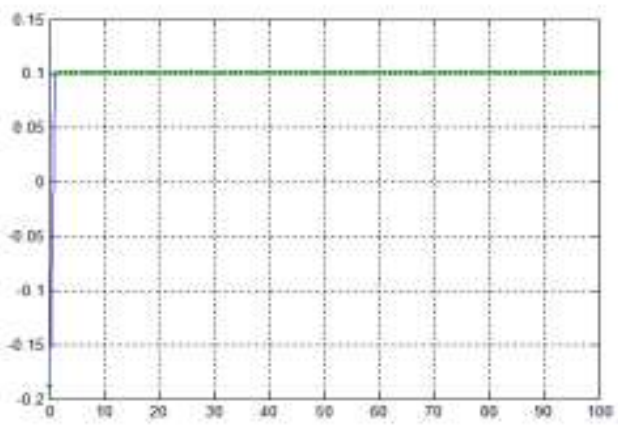

Table 2: Orbit of $\mathrm{F}(\mathrm{z})$ for $\mathbf{s}=\mathbf{0 . 8}, \mathbf{s}^{\prime}=\mathbf{0 . 2}$ at $\mathrm{z}_{0}=0.02786208647-0.03509673188 \mathrm{i}$

\begin{tabular}{|c|c|c|c|}
\hline $\begin{array}{c}\text { Number of } \\
\text { iteration i }\end{array}$ & $|\mathrm{F}(\mathrm{z})|$ & $\begin{array}{c}\text { Number of } \\
\text { iteration } \mathrm{i}\end{array}$ & $|\mathrm{F}(\mathrm{z})|$ \\
\hline 1 & 0.044812 & 7 & 0.12663 \\
\hline 2 & 0.10592 & 8 & 0.12664 \\
\hline 3 & 0.12207 & 9 & 0.12664 \\
\hline 4 & 0.12563 & 10 & 0.12664 \\
\hline 5 & 0.12642 & 11 & 0.12664 \\
\hline 6 & 0.12659 & 12 & 0.12664 \\
\hline
\end{tabular}

Here the value converges to a fixed point after 08 iterations 
Figure 2: Orbit of $F(z)$ for $\mathbf{s}=\mathbf{0 . 8}, s^{\prime}=\mathbf{0 . 2}$ at

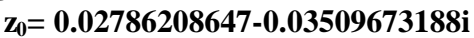

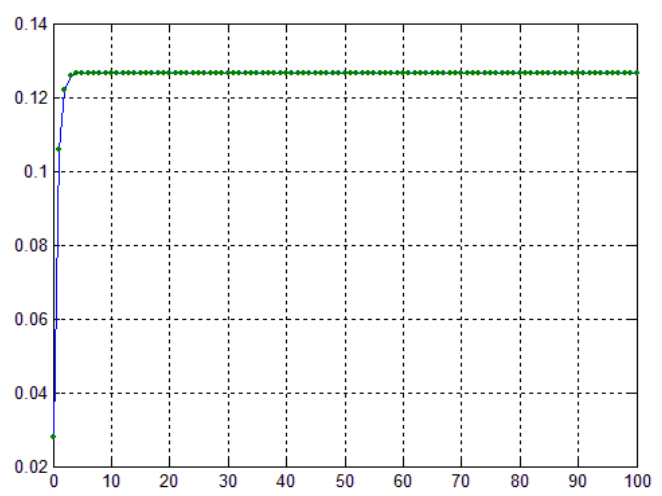

Table 3: Orbit of $F(z)$ for $s=0.5, s^{\prime}=0.6$ at $\mathrm{z}_{0}=\mathbf{- 0 . 0 3 5 3 4 2 8 3 4 2}+\mathbf{0 . 0 1 3 2 5 0 0 6 5 5 1 i}$

\begin{tabular}{|c|c|c|c|}
\hline $\begin{array}{c}\text { Number of } \\
\text { iteration i }\end{array}$ & $|\mathrm{F}(\mathrm{z})|$ & $\begin{array}{c}\text { Number of } \\
\text { iteration } \mathrm{i}\end{array}$ & $|\mathrm{F}(\mathrm{z})|$ \\
\hline 1 & 0.037745 & 11 & 0.20083 \\
\hline 2 & 0.082621 & 12 & 0.20096 \\
\hline 3 & 0.14137 & 13 & 0.20102 \\
\hline 4 & 0.17098 & 14 & 0.20105 \\
\hline 5 & 0.18589 & 15 & 0.20107 \\
\hline 6 & 0.19342 & 16 & 0.20108 \\
\hline 7 & 0.19721 & 17 & 0.20108 \\
\hline 8 & 0.19913 & 18 & 0.20108 \\
\hline 9 & 0.2001 & 19 & 0.20108 \\
\hline 10 & 0.20058 & 20 & 0.20108 \\
\hline
\end{tabular}

Here the value converges to a fixed point after 16 iterations

Figure 3: Orbit of $\mathrm{F}(\mathrm{z})$ for $0.5, \mathrm{~s}^{\prime}=\mathbf{0 . 6}$ at $z_{0}=-\mathbf{0 . 0 3 5 3 4 2 8 3 4 2}+\mathbf{0 . 0 1 3 2 5 0 0 6 5 5 1 i}$

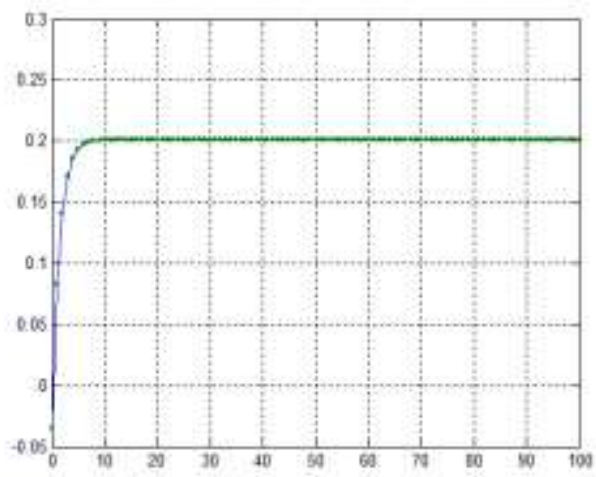

5. GENERATION OF RELATIVE SUPERIOR TRICRONS AND MULTICORNS:

We generate Relative Superior Tricorns and Multicorns. We present here some Relative Superior Tricorns and Multicorn for cubic and biquadratic function.
4.1 Relative Superior Tricorn for Quadratic function: Figure 1: Relative Superior Tricorn for $s=s^{\prime}=1$

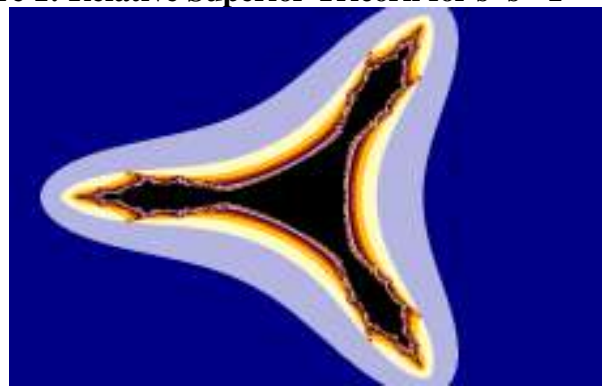

Figure 2: Relative Superior Tricorn for $s=0.1, s^{\prime}=0.3$

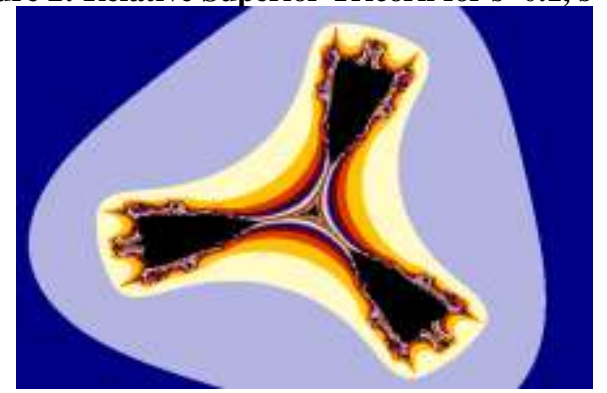

Figure 3: Relative Superior Tricorn for $s=0.6, s^{\prime}=0.4$

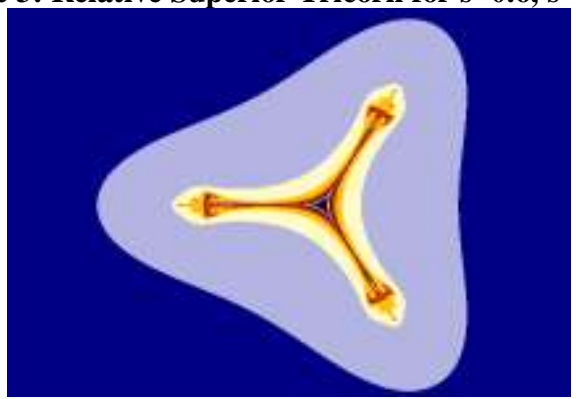

Figure 4: Relative Superior Tricorn for $s=0.1, s^{\prime}=0.1$

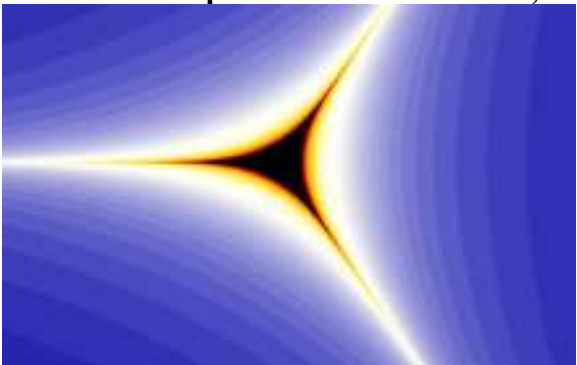

4.2 Relative Superior Multicorns for Cubic function: Figure 1: Relative Superior Multicorns for $s=1, s^{\prime}=1$

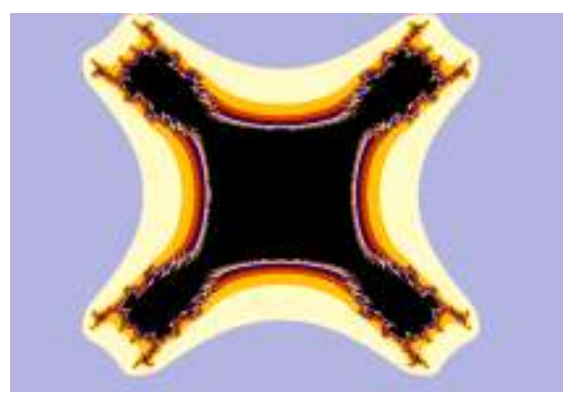


Figure 2: Relative Superior Multicorns for $s=0.1$,

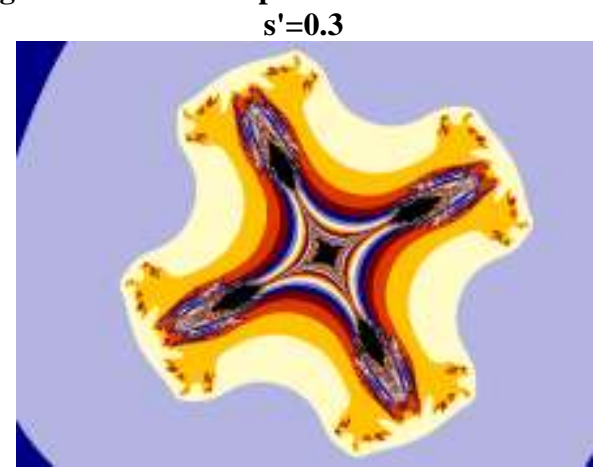

Figure 3: Relative Superior Multicorns for $s=0.5$, $s^{\prime}=0.4$

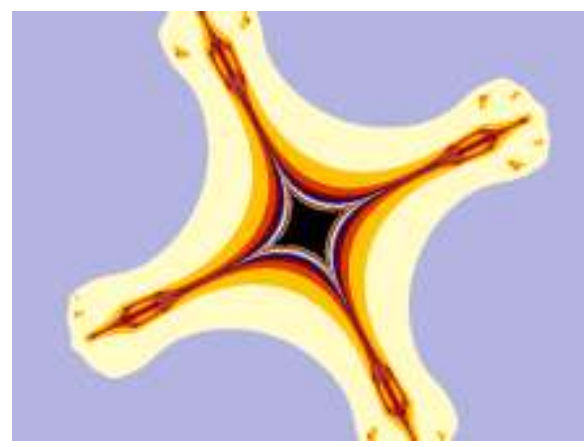

Figure 4: Relative Superior Multicorns $s=0.1, s^{\prime}=0.1$

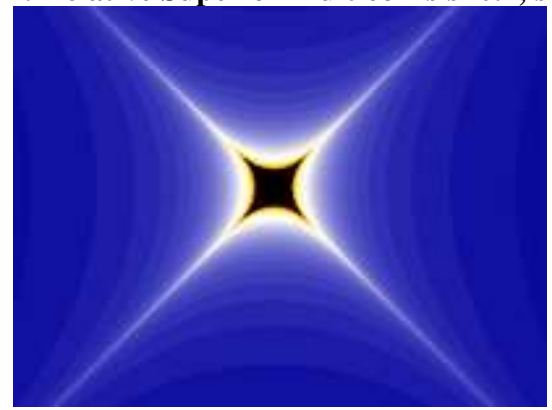

4.3 Relative Superior Multicorns for Bi-quadratic function:

Figure 1: Relative Superior Multicorns for $s=s^{\prime}=1$

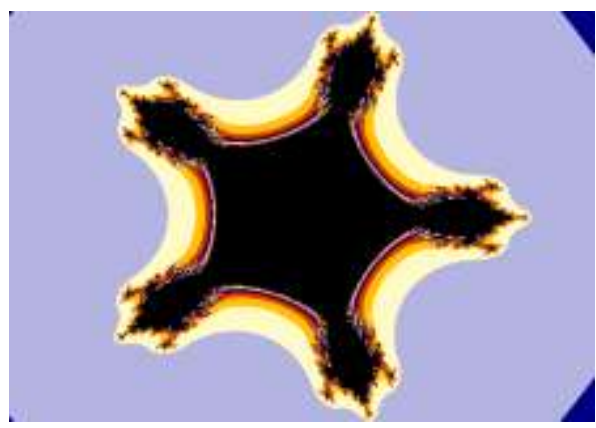

Figure 2: Relative Superior Multicorns for $s=0.5$

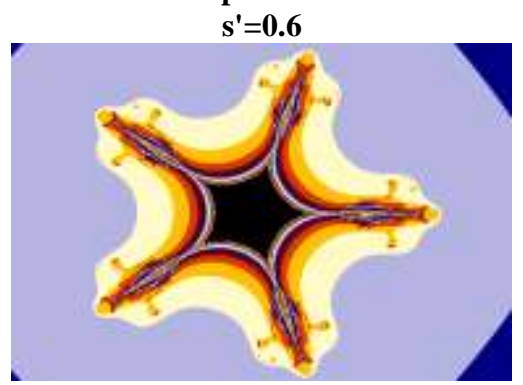

Figure 3: Relative Superior Multicorns for $s=0.8$,

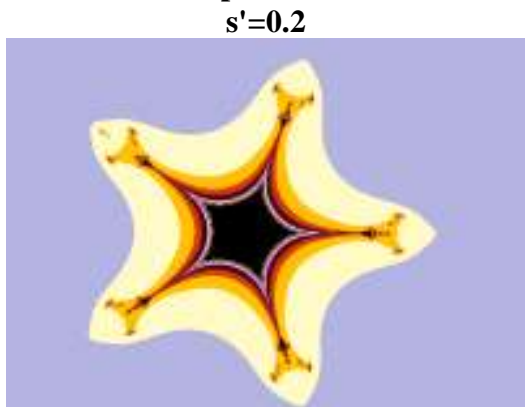

Figure 4: Relative Superior Multicorns for $s=0.1$,

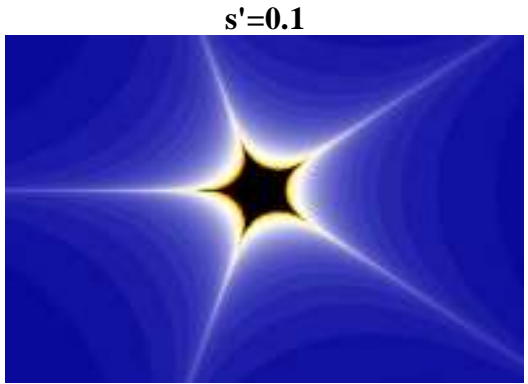

4.4. Generalization of Relative Superior Multicorns: Figure 1: Relative Superior Multicorns for $s=0.1$, $s^{\prime}=0.3, n=19$

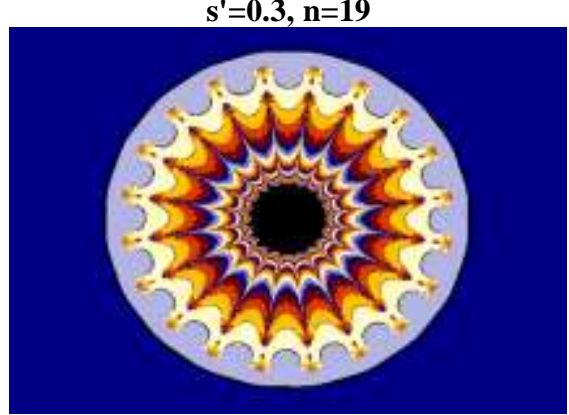

Figure 2: Relative Superior Multicorns for $s=0.8$, $s^{\prime}=0.2, n=19$

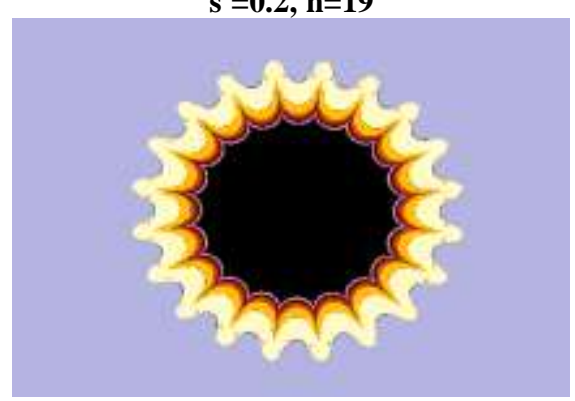


Figure 3: Relative Superior Multicorns for $s=0.1$, $s^{\prime}=0.3, n=52$

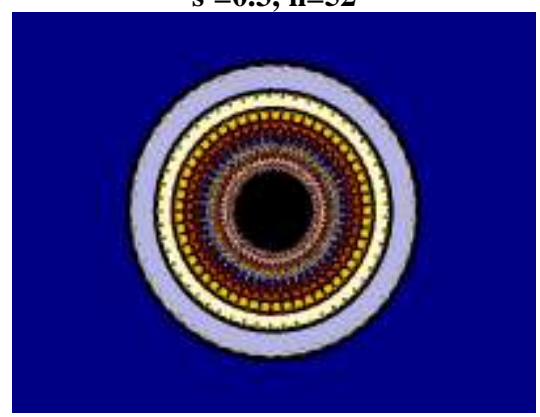

6. GENERATION OF RELATIVE SUPERIOR JULIA SETS FOR TRICORNS AND MULTICORNS:

We present here some filled Relative Superior Julia sets for quadratic, cubic and biquadratic function. 6.1 Relative Superior Julia sets for Quadratic:

Figure 1: Relative Superior Julia Set for $s=0.6, s^{\prime}=0.4$ $c=0.06415024553+0.03414122547 i$

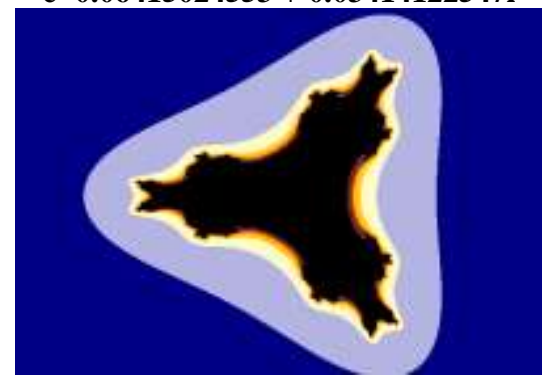

Figure 2: Relative Superior Julia Set for, $s=0.5, s^{\prime}=0.7$, $c=0.07056911734+0.03212328902 i$

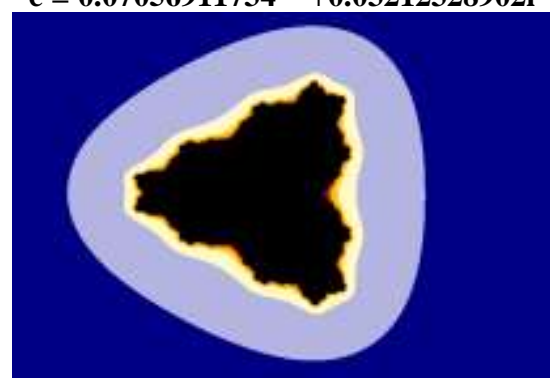

6.2 Relative Superior Julia sets for Cubic function:

Figure 1: Relative Superior Julia for $s=0.8, s^{\prime}=0.2$ $c=0.06175051669+0.03515650565 i$

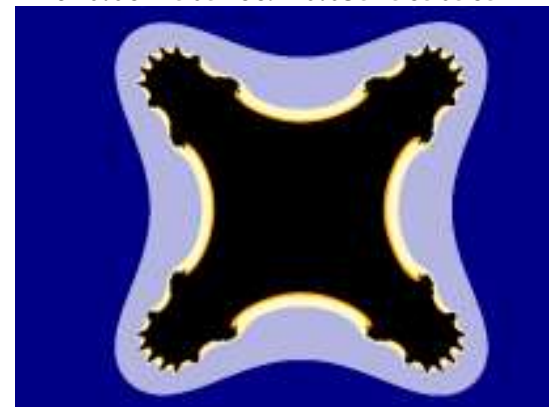

Figure 2: Relative Superior Julia Set for $s=0.5, s^{\prime}=0.4$ $c=-0.01341912254+0.001017666092 i$

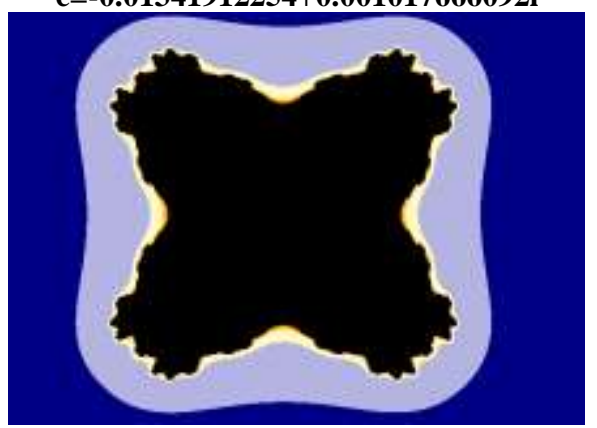

6.3 Relative Superior Julia sets for Bi-quadratic function:

Figure 1: Relative Superior Julia for $s=0.8, s^{\prime}=0.2$

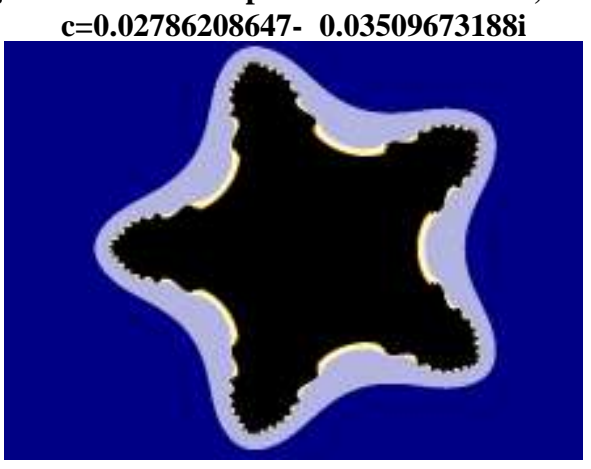

Figure 2: Relative Superior Julia for $s=0.5, s^{\prime}=0.6$ $c=-\mathbf{0 . 0 3 5 3 4 2 8 3 4 2}+\mathbf{0 . 0 1 3 2 5 0 0 6 5 5 1 i}$

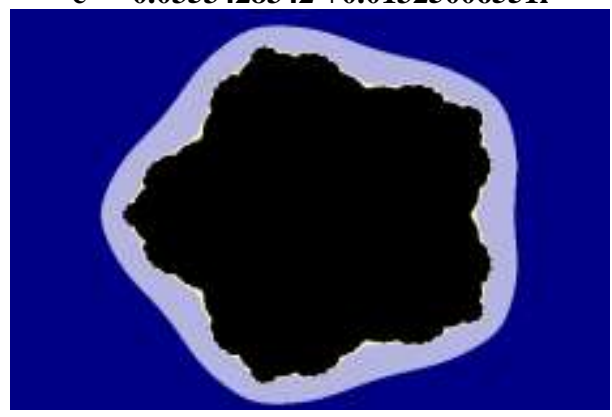

\section{CONCLUSION:}

In the dynamics of antipolynomial of complex polynomial $z^{\prime n}+c$, where $n \geq 2$, there exist many Tricorns and Multicorns antifractals for a value of $n$ with respect to Relative Superior orbit. Further, for the odd values of $n$, all the Relative Superior Multicorns are symmetrical objects, and for even values of $n$, all the Relative Superior Multicorns (including Relative Superior Tricorns) are symmetrical about $\mathrm{x}$-axis. 


\section{REFERENCES}

[1] W. D. Crowe, R. Hasson, P. J. Rippon, and P. E. D. Strain-Clark, "On the structure of the Mandelbar set", Nonlinearity (2)(4)(1989), 541553. MR1020441.

[2] Robert L. Devaney, "A First Course in Chaotic Dynamical Systems: Theory and Experiment", Addison-Wesley, 1992. MR1202237.

[3] S. Ishikawa, "Fixed points by a new iteration method", Proc. Amer. Math. Soc.44 (1974), 147150 .

[4] Manish Kumar, and Mamta Rani, "A new approach to superior Julia sets", J. nature. Phys. Sci, 19(2), (2005), 148-155.

[5] Eike Lau and Dierk Schleicher, "Symmetries of fractals revisited.", Math. Intelligencer (18)(1)(1996), 45-51. MR1381579 Zbl 0847.30018 .

[6] J. Milnor, "Dynamics in one complex variable; Introductory lectures", Vieweg (1999).

[7] Shizuo Nakane, and Dierk Schleicher, "Nonlocal connectivity of the tricorn and multicorns", Dynamical systems and chaos (1) (Hachioji, 1994), 200-203, World Sci. Publ., River Edge, NJ, 1995. MR1479931.

[8] Shizuo Nakane, and Dierk Schleicher, "On multicorns and unicorns: I. Antiholomorphic dynamics. hyperbolic components and real cubic polynomials", Internat. J. Bifur. Chaos Appl. Sci. Engrg, (13)(10)(2003), 2825-2844. MR2020986.
[9] Ashish Negi, "Generation of Fractals and Applications", Thesis, Gurukul Kangri Vishwvidyalaya, (2005).

[10] M.O.Osilike, "Stability results for Ishikawa fixed point iteration procedure", Indian Journal of Pure and Appl. Math., 26(1995), 937-945.

[11] M.O.Osilike, "Iterative construction of fixed points of multivalued operators of the accretive type", Sochow J.Math. 22(1996), 85-92.

[12] Pitgen, Jurgens and Saupe, "Chaos and Fractals, Springer-Verlag", NewYork, Inc., 1992.

[13] Mamta Rani, and Vinod Kumar, "Superior Mandelbrot sets", J. Korea Soc. Math. Educ. Ser. D; Res. Math. Educ. (8)(4)(2004), 279-291.

[14] B. E. Rhoades, "Fixed point iterations for certain nonlinear mappings", J. Math. Anal. 183 (1994), 118-120.

[15] K. Shirriff, "Fractals from Simple Polynomial Composite Functions," Computers \& Graphics, 17(6), Nov. 1993, pp 701-703.

[16] R. Winters, "Bifurcations in families of Antiholomorphic and biquadratic maps", Thesis, Boston Univ. (1990). 